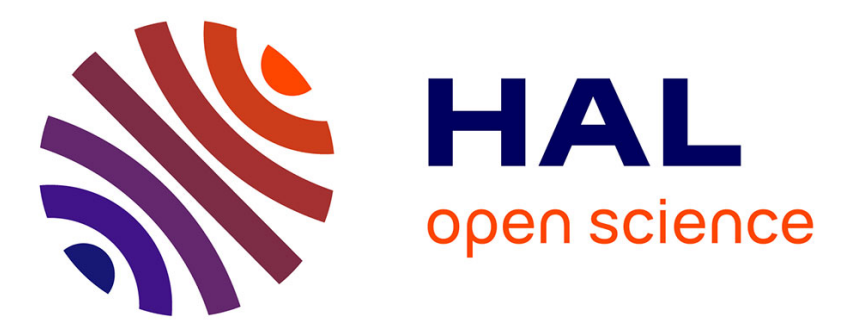

\title{
All-selenolate-protected eight-electron platinum/silver nanoclusters
}

\author{
Tzu-Hao Chiu, Jian-Hong Liao, Franck Gam, Isaac Chantrenne, Samia \\ Kahlal, Jean-Yves Saillard, C. W. Liu
}

\section{- To cite this version:}

Tzu-Hao Chiu, Jian-Hong Liao, Franck Gam, Isaac Chantrenne, Samia Kahlal, et al.. All-selenolateprotected eight-electron platinum/silver nanoclusters. Nanoscale, 2021, 13 (28), pp.12143-12148. 10.1039/d1nr02540f . hal-03330988

\section{HAL Id: hal-03330988 \\ https://hal.science/hal-03330988}

Submitted on 15 Sep 2021

HAL is a multi-disciplinary open access archive for the deposit and dissemination of scientific research documents, whether they are published or not. The documents may come from teaching and research institutions in France or abroad, or from public or private research centers.
L'archive ouverte pluridisciplinaire HAL, est destinée au dépôt et à la diffusion de documents scientifiques de niveau recherche, publiés ou non, émanant des établissements d'enseignement et de recherche français ou étrangers, des laboratoires publics ou privés. 


\title{
All-Selenolate-Protected Eight-Electron Platinum/Silver Nanoclusters
}

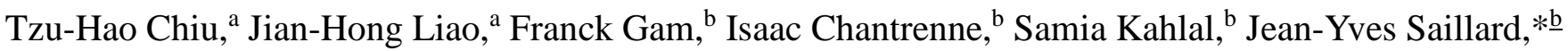 \\ and C. W. Liu*a \\ a.Department of Chemistry, National Dong Hwa University, Hualien 974301, Taiwan, Republic of China. \\ E-mail: chenwei@mail.ndhu.edu.tw \\ b.Univ. Rennes, CNRS, ISCR-UMR 6226, Rennes F-35000, France.
}

\begin{abstract}
First atomically and structurally precise platinum/silver superatoms protected by Se-donor ligands were synthesized in high yield by adopting ligand replacements on $\left[\mathrm{PtAg}{ }_{20}\left\{\mathrm{~S}_{2} \mathrm{P}\left(\mathrm{O}^{n} \mathrm{Pr}\right)_{2}\right\}_{12}\right]$ (3) with 12 equiv. of di-alkyl diselenophosph(in)ates. Structures of $\left[\mathrm{PtAg}_{20}\left\{\mathrm{Se}_{2} \mathrm{P}(\mathrm{OR})_{2}\right\}_{12}\right]\left(\mathrm{R}={ }^{n} \mathrm{Pr}(1 \mathrm{a}),{ }^{i} \mathrm{Pr}(1 \mathrm{~b})\right.$ and $\left[\mathrm{PtAg}{ }_{20}\left\{\mathrm{Se}_{2} \mathrm{P}\left(\mathrm{CH}_{2} \mathrm{CH}_{2} \mathrm{Ph}\right)_{2}\right\}_{12}\right]$ (2) were accurately determined by single-crystal $\mathrm{X}$-ray diffraction to reveal an eight-electron $\left[\mathrm{Pt}_{\mathrm{Ag}} \mathrm{Ag}_{12}\right]^{4+}$ icosahedral core embedded within a cube of eight silver(I) atoms and wrapped into a shell of twelve diselenophosph(in)ates. While the lowest energy absorption band of the Se-derivatives is red-shifted to longer wavelengths in comparison with S-analogue, it is blue-shifted in the emission spectra. DFT and TD-DFT calculations rationalize their electronic structures as that of 8-electron superatoms, with their HOMO and LUMO being the 1P and 1D levels, respectively. The two UV-vis lowest bands are associated with $1 \mathrm{P} \rightarrow 1 \mathrm{D}$ MMCT transitions. The blue shift observed for their S-analogue results from a larger HOMO-LUMO gap in the case of dithiolate ligands.
\end{abstract}

Metal nanoclusters (NCs) with precise compositions and structures are currently the subject of intense investigations due to the original properties associated with their specific nature.$^{1-7}$ In order to get a clear understanding of these properties, a precise knowledge of the NC structure is compulsory. Under this guideline, NC synthesis by doping hetero metals is very promising due to their potential property tuning controlled by dopants. ${ }^{8}$ Alloying group 11 metals with each other usually produces partial substitutions in several positions of the metal framework because of the close parentage of group 11 metals. ${ }^{9}$ On the other hand, when doping silver NCs with Pd and Pt, the group 10 metal tends to locate at the center of the polyhedral Ag kernel. ${ }^{10-11}$ Fully structurally characterized examples include $\mathrm{PtAg}_{9}{ }^{101} \mathrm{PtAg}_{14},{ }^{10 \mathrm{~m}}$ $\mathrm{PtAg}_{20},{ }^{10 \mathrm{f}} \mathrm{PtAg}_{24},{ }^{10 \mathrm{~g}} \mathrm{PtAg}_{26},{ }^{10 \mathrm{~h}} \mathrm{PtAg}_{28},{ }^{10 \mathrm{c}, \mathrm{d}} \mathrm{PtAg}_{31},{ }^{10 \mathrm{a}}$ and $\mathrm{PtAg}_{42}{ }^{10 \mathrm{k}}$ Most of them are supported by (or a combination of) thiolates, tertiary phosphines, halides or alkynes. So far, no selenolate-passivated platinum/silver NC has been reported.

Although more and more ligand-supported group 11-doped NCs have been reported, still only very few examples of silver or silver-rich nanoclusters protected by Se-donor ligands are known. ${ }^{12,14}$ Most of them originate from our group, such as the structurally characterized 8 electron silver superatoms $\left[\mathrm{Ag}_{20}\left\{\mathrm{Se}_{2} \mathrm{P}\left(\mathrm{O}^{i} \mathrm{Pr}\right)_{2}\right\}_{12}\right],{ }^{14 \mathrm{a}}$ and $\left[\mathrm{Ag}_{21}\left\{\mathrm{Se}_{2} \mathrm{P}(\mathrm{OEt})_{2}\right\}_{12}\right]^{+14 a}$ and their gold/silver alloy relatives $\left[\mathrm{AuAg}{ }_{20}\left\{\mathrm{Se}_{2} \mathrm{P}(\mathrm{OEt})_{2}\right\}_{12}\right]^{+},{ }^{14 a}$ $\left[\mathrm{AuAg}_{20}\left\{\mathrm{Se}_{2} \mathrm{P}\left(\mathrm{O}^{\prime} \mathrm{Pr}\right)_{2}\right\}_{12}\right]^{+14 \mathrm{~b}}$ and $\left[\mathrm{Au}_{3} \mathrm{Ag}_{18}\left\{\mathrm{Se}{ }_{2} \mathrm{P}\left(\mathrm{O}^{i} \mathrm{Pr}\right)_{2}\right\}_{12}\right]^{+} .^{14 \mathrm{~b}}$ An atomically precise, 18-electron silver superatom, $\left[\mathrm{Ag}_{44}(\mathrm{SePh})_{30}\right]^{4-}, \mathrm{primarily}$ characterized by ESI-MS and theoretically certified by DFT calculations, was reported by Pradeep, Negishi, and co-workers in $2013 .{ }^{13}$ The latest example is the 20-electron superatom, $\mathrm{Cd}_{12} \mathrm{Ag}_{32}(\mathrm{SePh})_{36}$, published by Bootharaju et al. in $2019 .{ }^{15}$ Thus the synthesis of silver-rich superatomic alloys protected by Se-donor ligands remains challenging and a convenient synthetic methodology is needed.

In the past few years we have developed a method of high-yield synthesis of Se-stabilized copper hydrides and silver-rich NCs by using a ligand exchange methods. ${ }^{14,16}$ It seemed natural to extend this approach to the design of Pt/Ag NCs, with the hope that not only the target alloys could be isolated, but also that we could explore the possibility of fine-tuning their optical properties. ${ }^{14}$ Another incentive in this endeavor is the frequently observed structural re-arrangement of metal cores, ${ }^{14}$ which indeed generate pseudo-isomers, primarily arising from the different bite distances of the chelating dithiolate and diselenolate ligands. ${ }^{17}$

Herein, we report the synthesis by ligand exchange reaction, characterization, crystal and electronic structures of three 8-electron Ptdoped diselenophosph(in)ates-protected silver superatoms. All three alloys have a similar Pt@Ag 20 metallic framework of $T_{h}$ symmetry. This high symmetry is favored by diselenophosphate/diselenophosphinate (dsep/dsepi) bite distance, which is $\sim 0.3 \AA$ larger than that of dithiophosphate (dtp), the latter favoring the lower $C_{2}$ symmetry for the Pt@ $\mathrm{Ag}_{20}$ core. ${ }^{1 \text { of }}$ Furthermore, the new compounds display different optical properties compared to their sulfur analogue. To the best of our knowledge these are the first, homoleptic Pt/Ag alloy cluster compounds protected entirely by Se-donor ligands.

A one-pot synthesis of $\mathrm{PtAg}_{20}(\mathrm{dsep})_{12}$ can be achieved by the reaction of twelve equiv. of $\left[\mathrm{NH}_{4}\right][\mathrm{dsep}]$ with $\left[\mathrm{PtAg} \mathrm{g}_{20}\left\{\mathrm{~S}_{2} \mathrm{P}\left(\mathrm{O}^{n} \mathrm{Pr}\right)_{2}\right\}_{12}\right]^{10 \mathrm{f}}$ in THF at $0^{\circ} \mathrm{C}$. The solution undergoes a color change from deep brown to orange. After rota-evaporation, the products were purified by hexanes to remove $\left[\mathrm{NH}_{4}\right]\left[\mathrm{S}_{2} \mathrm{P}\left(\mathrm{O}^{n} \mathrm{Pr}\right)_{2}\right]$, then $\mathrm{PtAg}_{20}\left\{\mathrm{Se}_{2} \mathrm{P}(\mathrm{OR})_{2}\right\}_{12}\left(\mathrm{R}={ }^{n} \mathrm{Pr}, \mathbf{1} \mathbf{a}\right.$; $\left.{ }^{i} \mathrm{Pr}, \mathbf{1 b}\right)$ can be obtained as deep orange solids in $85 \%$ yield after drying under vacuum. [PtAg $\left.20\left\{\mathrm{Se}_{2} \mathrm{P}\left(\mathrm{CH}_{2} \mathrm{CH}_{2} \mathrm{Ph}\right)_{2}\right\}_{12}\right]$ (2) was produced via a similar procedure by using dsepi ${ }^{18}$ instead of dsep ligands. These experiments must be performed in dark since the three resulting compounds are highly sensitive to light.

The X-ray structures of $\mathbf{1} \mathbf{a}, \mathbf{1} \mathbf{b}$, and $\mathbf{2}$ are very similar. That of $\mathbf{1 a}$ is depicted on Fig. $1 \mathrm{a}$. The $\mathrm{PtAg}_{20}$ core can be described as a Pt-centered $\mathrm{Ag}_{12}$ icosahedron inscribed in a cube made of $8 \mathrm{Ag}$ atoms, each of them capping a triangular face of the icosahedron, in such a way that the whole Pt@Ag $12 @ \mathrm{Ag}_{8}$ framework is of ideal $T_{\mathrm{h}}$ symmetry (Fig. 1b). The PtAg 20 core is stabilized by twelve dsep/dsepi ligands located on the twelve edges of the cube (Fig. 1c). The trimetallic triconnectivity $\left(\mu_{3}: \eta^{2}, \eta^{1}\right)$ of the ligands destroys the centrosymmetry (Fig. S1), lowering the ideal symmetry of the whole cluster to $T$. It is noteworthy that the sulfur precursor of $\mathbf{1}$ and $\mathbf{2}$, namely $\left[\mathrm{PtAg} \mathrm{g}_{20}\left\{\mathrm{~S}_{2} \mathrm{P}\left(\mathrm{O}^{n} \mathrm{Pr}\right)_{2}\right\}_{12}\right]^{10 \mathrm{f}} \quad(\mathbf{3})$ is of $C_{1}$ symmetry. Similarly, $\left[\mathrm{Ag}_{21}\left\{\mathrm{~S}_{2} \mathrm{P}\left(\mathrm{O}^{\prime} \mathrm{Pr}\right)_{2}\right\}_{12}\right]^{+}$, which is of $C_{3}$ symmetry, can be transformed into $\left[\mathrm{Ag}_{21}\left\{\mathrm{Se} \mathrm{e}_{2} \mathrm{P}(\mathrm{OEt})_{2}\right\}_{12}\right]^{+}$of $T$ symmetry via ligand replacement. ${ }^{14 a}$ Nowadays the ligand-exchange-induced structure transformation (LEIST), proposed by Jin, ${ }^{19}$ has become topical in the field of NC science. ${ }^{20}$ However, structure transformations induced by selenolate ligands remain scarce. ${ }^{12,14}$ Moreover, most of the works focused on LEIST involve nuclearity changes, that reported here maintains the whole cluster stoichiometry. 
The averaged $\mathrm{Pt}-\mathrm{Ag}_{\text {ico }}$ and $\mathrm{Ag}_{\text {ico-o }}-\mathrm{Ag}_{\text {ico }}$ distances in 1a are 2.759(4) $\AA$ and 2.901(9) $\AA$, respectively, showing strong Pt-Ag and Ag-Ag interactions in the superatomic core. The $\mathrm{Ag}_{\text {ico }}-\mathrm{Ag}_{\text {cap }}$ distances (avg. 2.959(8) $\AA$ ) are slightly longer than $A g_{\text {ico }}-\mathrm{Ag}_{\text {ico }}$ ones. All the metrical data of $\mathbf{1 a}$ are similar to that of $\mathbf{1 b}$ and $\mathbf{2}$ (Table S1). Astonishingly, the Pt-Agico and $\mathrm{Ag}_{\text {ico-}}-\mathrm{Ag}_{\text {ico }}$ distances observed in $\mathbf{3}$ (2.7601(7) $\AA$ and 2.9022(9) $\AA)^{10 f}$ are similar to that in $\mathbf{1}$ and $\mathbf{2}$. It clearly demonstrates that the nature of the protected ligands barely affects the metal-metal distances

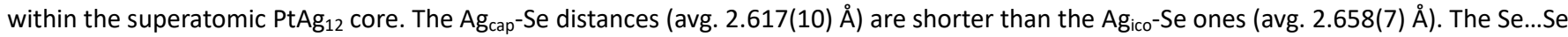
bite distances (avg. 3.688(2) $\AA$, 3.691(3) $\AA$, and 3.665(3) $\AA$ in 1a, 1b, and 2, respectively) are longer than that in 3 (avg. 3.412(4) $\AA$ ). Two probable factors account for the transformation of the metal framework from $C_{2}$ to $T_{h}$ upon ligand exchange. Firstly, the longer ligand bite distances in $\mathrm{PtAg}_{20}$ (dsep/desepi) ${ }_{12}$ releases the constrains around the metallic framework. Secondly, all the Se-protected superatomic clusters can only be synthesized by ligand exchange. In the course of the ligand replacement, the eight outer $\mathrm{Ag}_{\text {cap }}$ atoms are allowed to move away

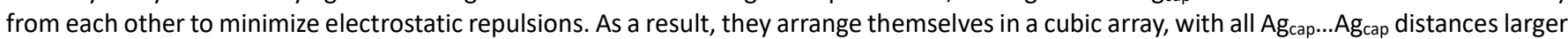
than $5 \AA ̊$. Intriguingly the reverse ligand-exchange reaction from dsep to dtp does not happen, suggesting that the stronger M-Se bonding may also play a role on the alloy stabilization.

Being of non-centrosymmetrical $T$ symmetry, the molecular structures of $\mathbf{1}$ and $\mathbf{2}$ are chiral. Unfortunately, they came out as racemic mixtures (Fig. S2-S3). We therefore could not obtain any chiroptical responses of $\mathbf{1}$ and $\mathbf{2}$ from CD spectroscopy, including for 1a, which crystallizes in a non-centrosymmetrical space group $\left(P 2_{1}\right)$ and contains only one enantiomer in its unit cell (Fig. 1d), but is likely a mixture of right- and left-handed crystals.

(a)

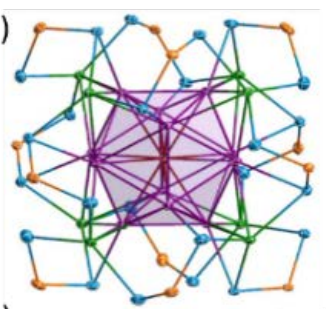

(b)

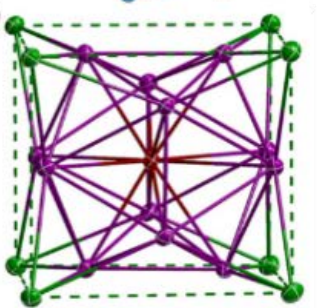

(d)

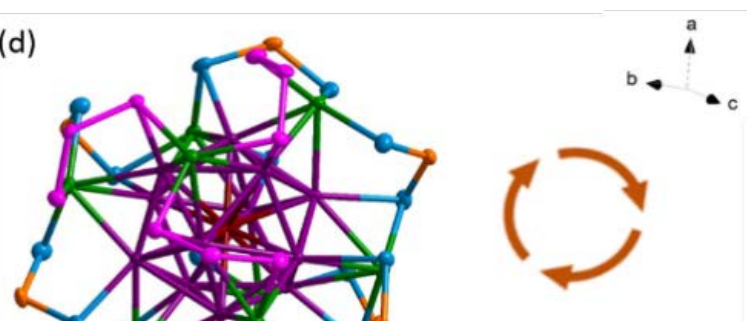

(c)
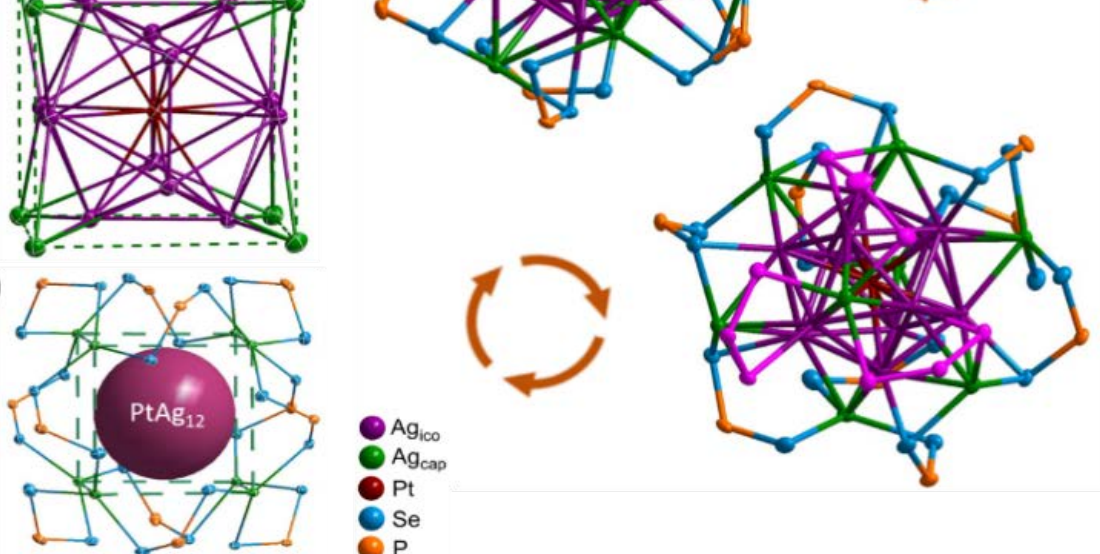

Pt

Se

Fig. 1 (a) Total structure of 1a with $n$-propoxy groups omitted for clarity. (b) A PtAg 12 kernel embedded in a cube made of eight capping Ag atoms. (c) Twelve bridging dsep/dsepi ligands located on each side of the $\mathrm{Ag}_{8}$ cube. (d) The packing diagram of 1a displays one enantiomer in the unit cell (chiral space group $\mathrm{P}_{2}$ ). Color code: dark red, $\mathrm{Pt}$ or $\mathrm{PtAg}_{12}$; violet, $\mathrm{Ag}_{\text {ico; }}$; green, $\mathrm{Ag}_{\text {cap }}$; blue, Se; orange, $\mathrm{P}$.

The ${ }^{31} \mathrm{P}\left\{{ }^{1} \mathrm{H}\right\}$ NMR spectrum of 1a displays one chemical shift centered at $74.1 \mathrm{ppm}$ and flanked by two sets of selenium satellites (ca. 609 and $709 \mathrm{~Hz}$ in Fig. 2a). The data suggest that the as-synthesized NC is highly symmetric in solution and that the two selenium atoms bound to the same phosphorus are not only chemically, but also magnetically inequivalent, a reflection on their binding modes ( $\mu_{3}: \eta^{2}, \eta^{1}$ in Fig. 2 b) derived from the X-ray structure (vide supra). Similar results are found for $\mathbf{1 b}$ and $\mathbf{2}$ (1) $\mathbf{b}: 67.3 \mathrm{ppm},{ }^{1} \mathrm{pSe}_{\mathrm{pS}}=597,711 \mathrm{~Hz} ; \mathbf{2}: 31.9 \mathrm{ppm}$ 454, $554 \mathrm{~Hz}$; Fig. S4-S5). The positive-ion ESI mass spectrum of 1a displays one intense band at $\mathrm{m} / \mathrm{z} 6145.3$, corresponding to the adduct ion $\left[\mathbf{1 a}+\mathrm{Ag}^{+}\right]^{+}$(calc. $\mathrm{m} / \mathrm{z}$ : 6145.1 in Fig. $2 \mathrm{c}$ ). In the ESI-MS spectrum of 2, there is one ion peak at 3625.6 corresponding to $\left[\mathbf{2}+\mathrm{Ag}^{+}+\mathrm{H}^{+}\right]^{2+}(\mathrm{calc}$. $\mathrm{m} / \mathrm{z}: 3626.7$ in Fig. S6). All simulated isotopic patterns match well with the experimental observations. 
(a)

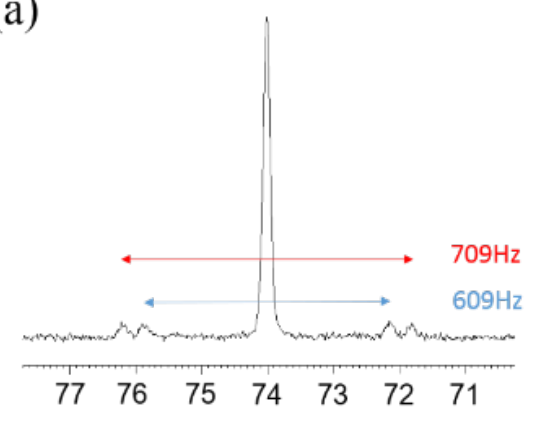

(b)

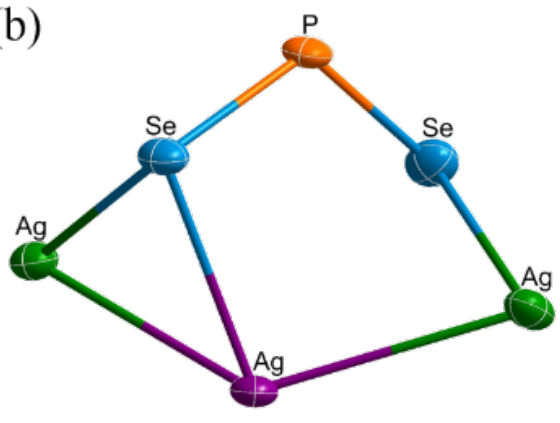

(c)

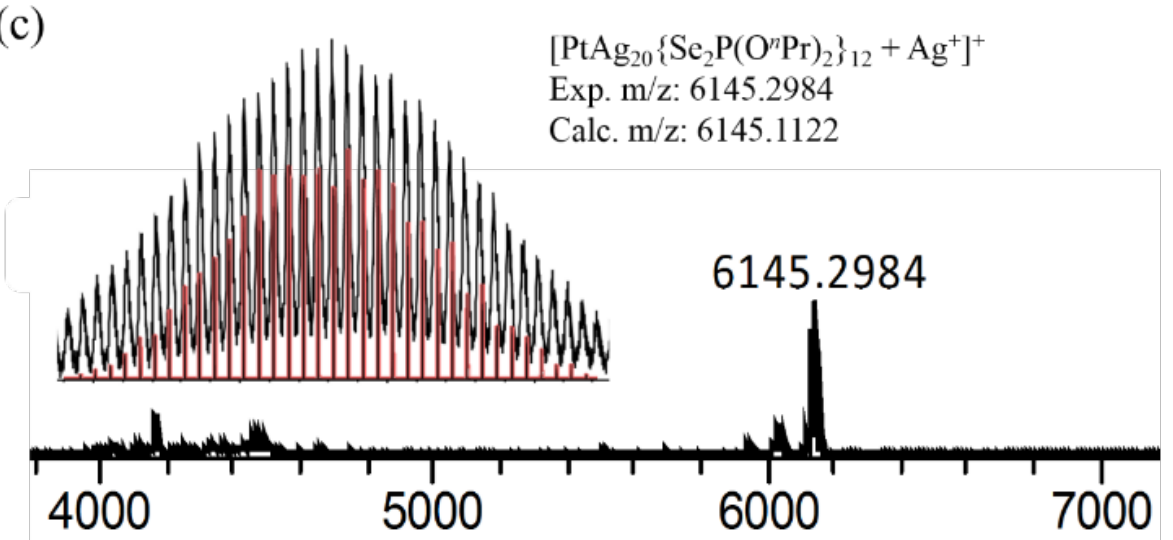

Fig. 2 (a) ${ }^{31} P\left\{{ }^{1} H\right\}$ NMR spectrum of 1a. (b) The coordination mode $\left(\mu 3: \eta^{2}, \eta^{1}\right)$ of a dsep/dsepi ligand. (c) Positive-mode ESI mass spectrum of 1a. Insets: experimental (black) and simulated (red) isotopic distribution of the ion peak $\left[\mathbf{1 a}+\mathrm{Ag}^{+}\right]^{+}$.

The UV-vis spectrum of 1a shows two bands centred at 388 and $466 \mathrm{~nm}$ (391, $470 \mathrm{~nm}$ for 1b; 414, $484 \mathrm{~nm}$ for 2) with the larger molar absorptivity observed at the former band (Table 1). Compared with 3, the absorption bands in 1a are red-shifted (Fig. 3). The stability of $\mathrm{PtAg}_{20}(\mathrm{dsep})_{12}$ in solution was further explored by time-dependent absorption spectroscopy (Fig. S7-S9). Compounds $\mathbf{1 a}$, $\mathbf{1 b}$ and $\mathbf{2}$ exhibit high stability in 2-MeTHF solution under the strict exclusion of light. The two major absorption bands retain both their shape and intensity over the course of one week when the solution is kept in dark. Under light, decomposition starts within 30 minutes, and the intensity of the two absorption bands decreases with time. Eventually, the absorption bands are barely discernable after two hours, indicating that three the $\mathrm{PtAg}_{20} \mathrm{NCs}$ are highly sensitive to visible light.

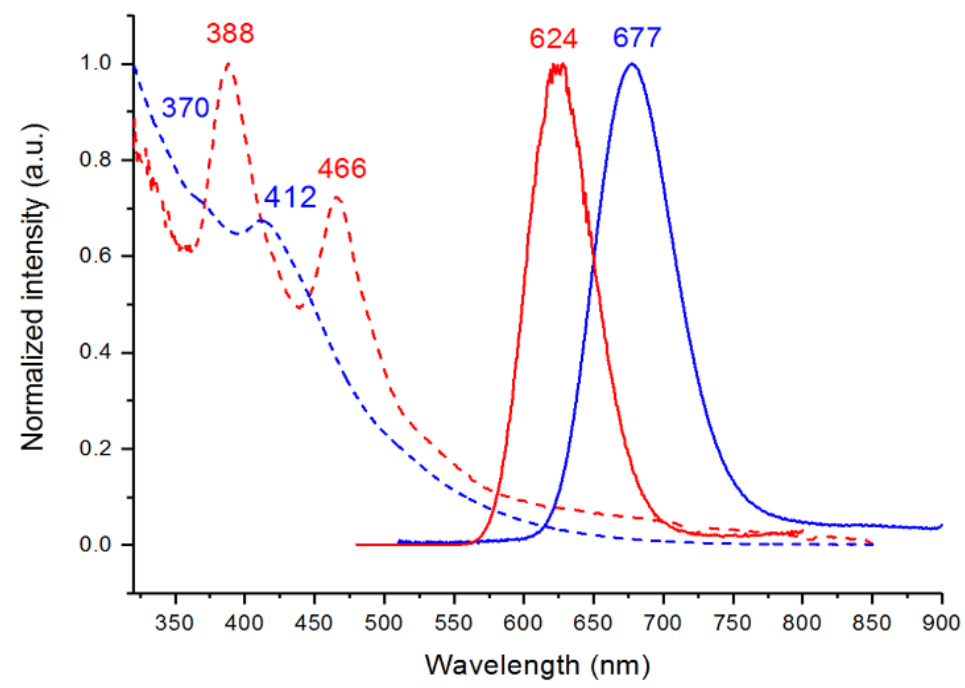

Fig. 3 Normalized absorption (dash line) and emission spectra (solid line) of $\left[\mathrm{PtAg}_{20}\left\{\mathrm{~S}_{2} \mathrm{P}\left(\mathrm{O}^{n} \mathrm{Pr}\right)_{2}\right\}_{12}\right]\left(3\right.$, blue curve) and $\left[\mathrm{PtAg}{ }_{20}\left\{\mathrm{Se}_{2} \mathrm{P}\left(\mathrm{O}^{n} \mathrm{Pr}\right)_{2}\right\}_{12}\right]$ (1a, red curve). 
The 77K photoluminescent (PL) spectra of 1a, $\mathbf{1 b}$ and $\mathbf{2}$ (Fig. 3, S10-S11) in 2-MeTHF exhibit one structureless emission band centered at $624 \mathrm{~nm}, 621 \mathrm{~nm}$, and $629 \mathrm{~nm}$, respectively. They are blue-shifted relative to their dithiophosphate-protected relative 3. The time-resolved photoluminescence spectrum (77K) of $\mathbf{1 a}, \mathbf{1} \mathbf{b}$, and $\mathbf{2}$ exhibit a single exponential decay curve (Fig. S12-S14). The lifetimes ( $\tau$ ) of $\mathbf{1 a}$ and $\mathbf{1} \mathbf{b}$ are $8.5 \mu \mathrm{s}$ and $8.4 \mu \mathrm{s}$, which are slightly shorter than in $\mathbf{2}(\tau=12.3 \mu \mathrm{s})$. With emission lifetimes in the microsecond range, phosphorescence is suggested. The corresponding Stokes shifts in $1 \mathrm{a}\left(5400 \mathrm{~cm}^{-1}\right)$ and $\mathbf{1 b}\left(5200 \mathrm{~cm}^{-1}\right)$ are slightly larger than in $2\left(4800 \mathrm{~cm}^{-1}\right)$. The smaller Stokes shift in $\mathbf{2}$ indicates that there is less non-radiative relaxation (vibrational relaxation) than for $\mathbf{1 a}$ and $\mathbf{1 b}$, i.e. better emission efficiency. As a result, the weak orange emission of $\mathbf{2}$ can be barely seen in solution at ambient temperature, but that $\mathbf{1 a}$ and $\mathbf{1 b}$ were not observed. The lifetime of $\mathbf{2}$ at ambient temperature, which is possibly quenched by the solvent, was largely decreased. Relevant photophysical data of $\mathbf{1}$ and 2 are reported in Table 1.

Intriguingly a general trend is observed on both absorption and emission spectra of the $M @ A g_{20}(d s e p)_{12}(M=A g, A u, P t) N C s$ of $T$ symmetry. That is, a spectrum shifting to higher energy upon doping with a hetero-metal at the cluster center. ${ }^{14 a}$ While there is not much difference in the absorption wavelengths between the $\mathrm{Au}(390,470 \mathrm{~nm})$ and $\mathrm{Pt}(388,466 \mathrm{~nm})$ alloys, even though their cluster charges are different, a significant blue-shift (624 (1a), and $674 \mathrm{~nm}\left(\mathbf{A u A g}_{\mathbf{2 0}}\right)$ is observed in the Pt-doped NCs.

The $\mathrm{Ag}\left(3 \mathrm{~d}_{5 / 2}\right)$ XPS spectrum (Fig. S18-S20) exhibits a binding energy (BE) at 367.87, 367.59, and $367.85 \mathrm{eV}$ in $\mathbf{1 a}$, 1b, and 2, respectively. A peak deconvolution can be resolved into two bands, confirming that the average valence state of $\mathrm{Ag}$ is between $\mathrm{Ag}(0)(368.2 \mathrm{eV})$ and $\mathrm{Ag}(\mathrm{I})$ (ca. $1 \mathrm{eV}$ below $368.2 \mathrm{eV}$ ). ${ }^{21}$ These recorded BEs are comparable with that of $\mathbf{3}(367.50 \mathrm{eV})$. The elemental analysis (EA) was used to test the purity. For example, the carbon and hydrogen contents of $\mathbf{1 b}$ are $13.91 \%$ and $2.98 \%$, which are close to the theoretical values (C:14.32\%, $\mathrm{H}: 2.8 \%)$. The TGA spectra were also employed to test the purity and thermal stability of $\mathbf{1 a}, \mathbf{1} \mathbf{b}, \mathbf{2}$ and $\mathbf{3}$ (Fig. S21-S24). The TGA curves show that $\mathbf{1 a}, \mathbf{1 b}$, and $\mathbf{3}$ start to decompose at $190{ }^{\circ} \mathrm{C}$, and the curve becomes flat from $210{ }^{\circ} \mathrm{C}$ to $400{ }^{\circ} \mathrm{C}$ in which the residual fragment can be calculated as $\operatorname{PtAg}_{20} \mathrm{E}_{24}(\mathrm{E}=\mathrm{Se}$ for $\mathbf{1 a}, \mathbf{1} \mathbf{b}$, and $\mathbf{2} ; \mathrm{E}=\mathrm{S}$ for $\mathbf{3}$ ). Compound $\mathbf{2}$ showed better thermal stability, with a decomposition temperature around $300^{\circ} \mathrm{C}$. Further weight loss of $\mathrm{S} / \mathrm{Se}$ occurs when the temperature is elevated above $400{ }^{\circ} \mathrm{C}$. The experimental weight loss of $29.8 \%$, $\mathbf{2 9 . 7 \%}$, and $\mathbf{4 1 . 5 \%}$ for $\mathbf{1 a}, \mathbf{1} \mathbf{b}$, and $\mathbf{2}$, respectively, is consistent with the theoretical value of $\mathbf{2 9 . 6 \%}$ (for $\mathbf{1 a}$ and $\mathbf{1 b}$ ) and $\mathbf{4 0 . 5 \%}$ (for $\mathbf{2}$ ), calculated as following: $\left[\left(12 \mathrm{M}_{\mathrm{L}}-24 \mathrm{M}_{\mathrm{Se}}\right) /\left(\mathrm{M}_{\mathrm{Pt}}+20 \mathrm{M}_{\mathrm{Ag}}+12 \mathrm{M}_{\mathrm{L}}\right)\right] * 100 \%$ (where $\mathrm{M}$ represents the mass and $\mathrm{L}$ the ligands). The experimental weight loss of 3 (35.8\%) matches well with the theoretical value (36.4\%).

DFT calculations at the BP86/Def2TZVP level (see Computational Details) were performed on simplified models of 1-2, and 3, respectively, namely $\left.\left[\mathrm{PtAg}_{20}\left\{\mathrm{Se}_{2} \mathrm{PH}_{2}\right)_{2}\right\}_{12}\right]\left(\mathbf{1}^{\prime}\right)$ and $\left.\left[\mathrm{PtAg}_{20}\left\{\mathrm{~S}_{2} \mathrm{PH}_{2}\right)_{2}\right\}_{12}\right]\left(\mathbf{3}^{\prime}\right)$. Two geometries were considered, the $T$ arrangement of 1-2 and the

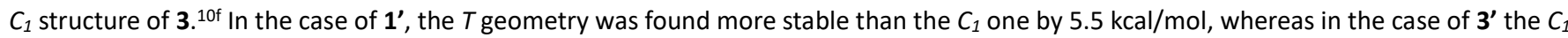
structure was found the most stable by $1.9 \mathrm{kcal} / \mathrm{mol}$. Although small, these free energy differences are in line with the reported $\mathrm{X}$-ray structures. The optimized $T$ structure of 1' matches with the X-ray structures of 1-2 (Table S1), with slightly larger bond distances, as expected at this level of theory. The metal atomic charges computed within the natural atomic orbital (NAO) formalism are $-1.18(\mathrm{Pt}),+0.23(\mathrm{Ag}$ ico $)$ and $+0.56\left(\mathrm{Ag}_{\text {cap }}\right)$. The corresponding averaged values of the dithiolato relative $3^{\prime}$ are similar: $-1.19(\mathrm{Pt}),+0.25\left(\mathrm{Ag}_{\text {ico }}\right)$ and $+0.62\left(\mathrm{Ag}_{\text {cap }}\right)$. That of the homometallic relative $\left.\left[\mathrm{Ag}_{21}\left\{\mathrm{Se}_{2} \mathrm{PH}_{2}\right)_{2}\right\}_{12}\right]^{+}$of $T$ symmetry are: $-0.4\left(\mathrm{Ag}_{\text {center }}\right),+0.21\left(\mathrm{Ag}_{\text {ico }}\right)$ and $+0.57\left(\mathrm{Ag}_{\mathrm{cap}}\right)$. The Wiberg bond indices (Table S1) indicate strong, intermediate and weak bonding for the $\mathrm{Pt}-\mathrm{Ag}_{\mathrm{ico}}, \mathrm{Ag}_{\mathrm{ico}}-\mathrm{Ag}_{\mathrm{ico}}$ and $\mathrm{Ag}$ ico- $\mathrm{Ag}$ cap contacts, respectively. These results are consistent with the classical view ${ }^{10 f, 14,16}$ of an 8-electron superatomic icosahedral $\left[\mathrm{PtAg}_{12}\right]^{4+}$ core stabilized by $8 \mathrm{Ag}(\mathrm{I})$ cations in a trigonal planar $\mathrm{AgE}_{3}(\mathrm{E}$ $=\mathrm{S}$, Se) coordination mode and twelve formally anionic dsep/dtp ligands. The negative charge on Pt is consistent with the usual polarization of the superatomic $1 \mathrm{~S}$ level on the icosahedron center. The Kohn-Sham diagram of $\mathbf{1}^{\prime}$ ( $T$ symmetry) is shown in Fig. 4. It exhibits a substantial HOMO-LUMO gap of $1.82 \mathrm{eV}$, separating the 1P superatomic orbitals from the $t$ component of the $1 \mathrm{D}$ set. Indeed, within the $T$ symmetry of the molecule, the 1D level splits into one $t$ and one $e$ components, the latter lying above the former. An Ag-Se antibonding level of $a$ symmetry is intercalated between the two 1D components. The TD-DFT-simulated UV-vis spectrum is shown in Fig. S25. The two bands it displays at 454 and $374 \mathrm{~nm}$ are in a very good agreement with their experimental counterparts reported for 1-2 (Table 1). That of lowest energy corresponds to a $\mathrm{HOMO} \rightarrow \mathrm{LUMO}$, i.e. $1 \mathrm{P} \rightarrow 1 \mathrm{D}(t)$, transition and the other one is of dominant $1 \mathrm{P} \rightarrow 1 \mathrm{D}(e)$ character. Therefore, both transitions are associated with significant intraicosahedral $\mathrm{Pt} \rightarrow \mathrm{Ag}$ transfer. Replacing Se by $\mathrm{S}$ in $\mathbf{1}^{\prime}$ and keeping the $T$ high symmetry of the cluster induces a blue shift of the two low-energy bands to 430 and $357 \mathrm{~nm}$, respectively, as the result of a larger HOMO-LUMO gap. In the less symmetrical $3^{\prime}$, these two bands are merged into a single one peaking at $408 \mathrm{~nm},{ }^{10 \mathrm{f}}$ in a pretty good agreement with experiment. The TDDFT-computed CD spectrum of one of the $\mathbf{1}^{\prime}$ enantiomers is also shown in Fig. S25. Its major features match with the two computed absorption bands and therefore are of important MMCT nature. The minor but non-negligible contribution of the chiral ligand shell to the 1P and 1D orbitals (24$33 \%$ ) is likely to play a significant role in the CD behaviour.

Table 1. Photophysical data of 1a, 1b, 2, and 3.

\begin{tabular}{|c|c|c|c|c|c|c|}
\hline Comp. & State & $\begin{array}{c}\text { Absorbance } \\
\lambda_{\text {abs }}(\mathrm{nm}), \varepsilon\left(\mathrm{M}^{-1} \mathrm{~cm}^{-1}\right)\end{array}$ & $\begin{array}{c}\text { Excitation } \\
\lambda_{\mathrm{ex}}(\mathrm{nm}) \\
\end{array}$ & $\begin{array}{l}\text { Emission } \\
\lambda_{\mathrm{em}}(\mathrm{nm}) \\
\end{array}$ & Stokes Shift $\left(\mathrm{cm}^{-1}\right)$ & $\begin{array}{l}\text { Life time } \\
\tau(\mu \mathrm{s})\end{array}$ \\
\hline \multirow{2}{*}{$1 \mathrm{a}$} & 2-Me-THF (298 K) & 388 (35600), 466 (25600) & -- & -- & \multirow{2}{*}{5400} & -- \\
\hline & 2-Me-THF (77 K) & -- & $375,388,460$ & 624 & & 8.5 \\
\hline \multirow{2}{*}{$1 b$} & 2-Me-THF (298 K) & 391 (35900). $470(28700)$ & -- & -- & \multirow{2}{*}{5200} & -- \\
\hline & 2-Me-THF (77 K) & -- & $374,390,463$ & 621 & & 8.4 \\
\hline \multirow{2}{*}{2} & 2-Me-THF (298 K) & $414(36000), 484(31700)$ & 414,485 & 663 & 5600 & 0.8 \\
\hline & 2-Me-THF (77 K) & -- & 407,477 & 629 & 4800 & 12.3 \\
\hline \multirow[b]{2}{*}{3} & 2-Me-THF (298 K) & $369(43000), 412(60600)$ & -- & -- & \multirow[b]{2}{*}{9500} & -- \\
\hline & 2-Me-THF (77 K) & -- & $\begin{array}{c}363,389 \\
448 \\
\end{array}$ & 677 & & 18.3 \\
\hline
\end{tabular}




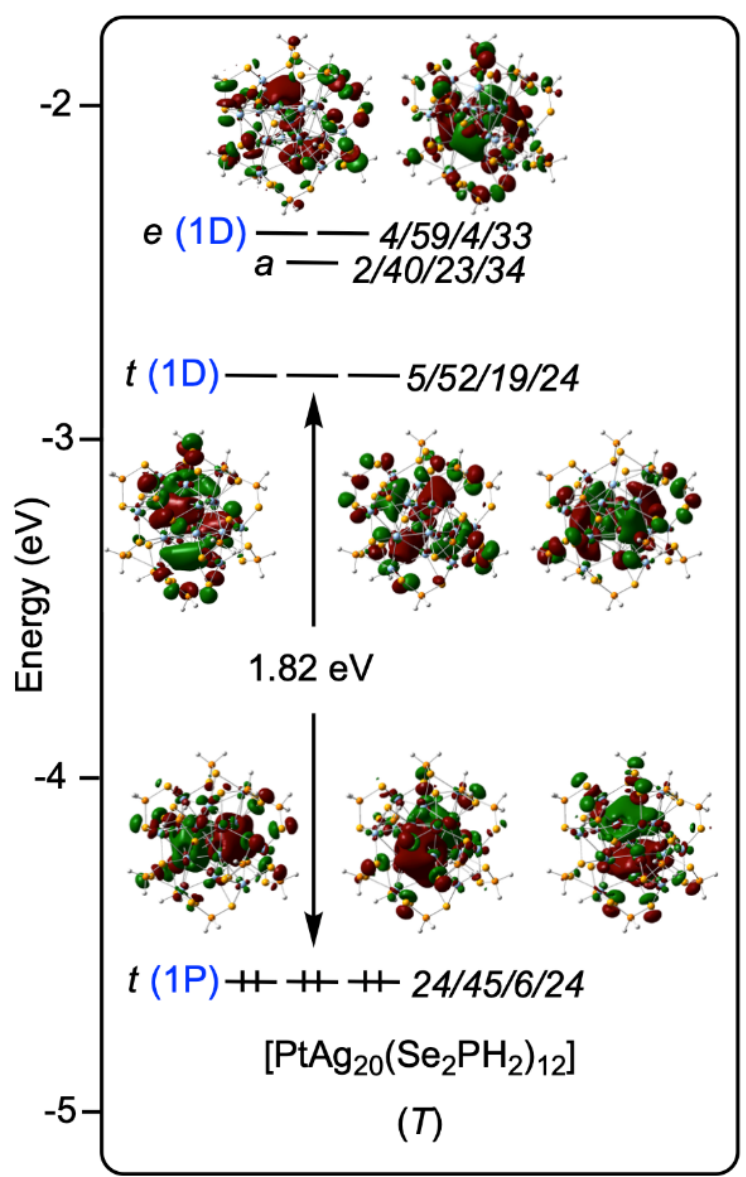

Fig. 4 Kohn-Sham MO diagram of 1' with atom participations (\%) indicated as follows: $\left.\mathrm{Pt} / \mathrm{Ag}_{\text {ico }}\right)_{12} /\left(\mathrm{Ag}_{\text {cap }}\right)_{8} /(\text { ligand })_{12}$

\section{Conclusions}

In summary, the first examples of platinum/silver bimetallic alloy NCs protected by Se-donor ligands are reported, with full characterization by single-crystal X-ray diffraction, NMR, ESI-MS, and theoretical analysis. The symmetry of the metal framework is modified from $C_{2}$ to $T_{h}$ upon changing the passivated shell from S to Se. The Se-passivated PtAg 20 NCs are very stable in dark for more than one week, but are highly sensitive to light. Overall, this work demonstrates that the ligand-exchange strategy indeed provides a convenient protocol to synthesize Se-protected alloy NCs, which are difficult to make. Hopefully, such reactions accompanied with structural transformations will soon provide a new insight in the development of structural isomers in the nanoscience domain.

\section{Acknowledgements}

This work was supported by the Ministry of Science and Technology of Taiwan (MOST 109-2113-M-259-008; 108-2923-M-259-001), the France-Taiwan ANR-MOST 2018 program (project Nanoalloys) and the GENCI French national computer resource center (grant A0030807367).

\section{Conflicts of interest}

There are no conflicts to declare.

\section{Notes and references}

1. R. Jin, C. Zeng, M. Zhou and Y. Chen, Chem. Rev., 2016, 116, 10346-10413.

2. I. Chakraborty and T. Pradeep, Chem. Rev., 2017, 117, 8208-8271.

3. Q. Wang, Y. Lin and K. Liu, Acc. Chem. Res., 2015, 48, 1570-1579.

4. W. Kurashigea, Y. Niihoria, S. Sharmaa and Y. Negishi, Coord. Chem. Rev., 2016, 320-321, 238-250. 
5. J. F. Parker, C. A. Fields-Zinna and R. W. Murray, Acc. Chem. Res., 2010, 43, 1289-1296.

6. R. Jin and K. Nobusada, Nano Res., 2014, 7, 285-300.

7. S. Sharma, K. K. Chakrahari, J. Y. Saillard and C. W. Liu, Acc. Chem. Res., 2018, 51, 2475-2483.

8. X. Kang, Y. Li, M. Zhu and R. Jin, Chem. Soc. Rev., 2020, 49, 6443-6514.

9. (a) S. Yang, J. Cha, T. Chen, B. Rao, Y. Pan, H. Yu and M. Zhu, Inorg. Chem., 2017, 56, 1771-1774; (b) J. Yzn, S. Malola, C. Hu, J. Peng, B. Ditrich, B. K. Teo, H. Häkkinen, L. Zheng and N. Zheng, Nat. Commum., 2018, 9,3357; (c) S. Wang, X. Meng, A. Das, T. Li, Y. Song, T. Cao, X. Zhu, M. Zhu and R. Jin, Angew. Chem., Int. Ed., 2014, 53, 2376-2380.

10. (a) X. Kang, S. Jin, L. Xiong, X. Wei, M. Zhou, C. Qin, Y. Pei, S. Wang and M. Zhu, Chem. Sci., 2020,1,1691-1697; (b) S. Yang, J. Chai, Y. Lv, T. Chen, S. Wang, H. Yu and M. Zhu, Chem. Commun., 2018, 54, 12077-12080 ; (c) X. Kang, M. Zhou, S. Wang, S. Jin, G. Sun, M. Zhu and R. Jin, Chem. Sci., 2017, 8, 2581-2587; (d) X. Kang, L. Huang, W. Liu, L. Xiong, Y. Pei, Z. Sun, S. Wang, S. Wei and M. Zhu, Chem. Sci., 2019, 10, 8685-8693 ; (e) X. Kang, L. Xiong, S. Wang, H. Yu, S. Jin, Y. Song, T. Chen, L. Zheng, C. Pan, Y. Pei and M. Zhu, Chem.-Eur. J., 2016, 22,17145-17150 ; (f) T.-H. Chiu, J.-H. Liao, F. Gam I. Chantrenne, S. Kahlal, J.-Y. Saillard and C. W. Liu, J. Am. Chem. Soc., 2019, 141, 1295712961 ; (g) X. Liu, J. Yuan, C. Yao, J. Chen, L. Li, X. Bao, J. Yang and Z. Wu, J. Phys. Chem. C, 2017, 121,13848-13853; (h) L. He, J. Yuan, N. Xia, L. Liao, X. Liu, Z. Gan, C. Wang, J. Yang and Z. Wu, J. Am. Chem. Soc., 2018, 140, 3487-3490; (i) M. S. Bootharaju, S. M. Kozlov, Z. Cao, A. Shkurenko, A. M. El-Zohry, O. F. Mohammed, M. Eddaoudi, O. M. Bakr, L. Cavallo and J.-M. Basset, Chem. Mater., 2018, 30, 27192725; (j) X. Kang, X. Wei, S. Jin, Q. Yuan, X. Luan, Y. Pei, S. Wang, M. Zhu and R. Jin, Proc. Nat. Acad. Sci. USA, 2019, 116, 18834-18840; (k) H. Shen and T. Mizuta, Chem. - Asian J., 2017, 12 , 2904-2907; (I) W. Sun, S. Jin, W. Du, X. Kang, A. Chen, S. Wang, H. Sheng and M. Zhu, Eur. J. Inorg. Chem., 2020, 2020, 590-594; (m) X. Lin, K. Sun, X. Fu, X. Ren, Y. Yang, C. Liu and J. Huang, J. Phys. Chem. C, 2021, 125, 2194-2201.

11. (a) S. K. Barik, T.-H. Chiu, Y.-C. Liu, M.-H. Chiang, F. Gam, I. Chantrenne, S. Kahlal, J.-Y. Saillard and C. W. Liu, Nanoscale, 2019, 11, 1458114586; (b) M. S. Bootharaju, C. P. Joshi, M. R. Parida, O. F. Mohammed and O. M. Bakr, Angew. Chem., Int. Ed., 2016, 55, 922-926.

12. X. Kang and M. Zhu, small, 2019, 15, 1902703.

13. I. Chakraborty, W. Kurashige, K. Kanehira, L. Gell, H. Häkkinen, Y. Negishi, T. Pradeep, J. Phys. Chem. Lett. 2013, 4, 3351-3355.

14. (a) W.-T. Chang, P.-Y. Lee, J.-H. Liao, K. K. Chakrahari , S. Kahlal, Y.-C. Liu, M.-H. Chiang, J.-Y. Saillard and C. W. Liu, Angew. Chem., Int. Ed., 2017, 56, 10178-10182; (b) W.-T. Chang, S. Sharma, J.-H. Liao, S. Kahlal, Y.-C Liu, M.-H. Chiang, J.-Y. Saillard and C. W. Liu, Chem.Eur. J., 2018, 25, 14352-14357.

15. M. S. Bootharaju, H. Chang, G. Deng, S. Malola, W. Beak, H. Häkkinen, N. Zheng and T. Hyeon, J. Am. Chem. Soc., 2019, 141, 8422-8425.

16. R. S. Dhayal, J.-H. Liao, X. Wang, Y.-C. Liu, M.-H. Chiang, S. Kahlal, J.-Y. Saillard and C. W. Liu, Angew. Chem., Int. Ed., 2015, 54, 1360413608.

17. T. S. Lobana, J.-C. Wang and C. W. Liu, Coord. Chem. Rev., 2007, 251, 91-110.

18. A. V. Artem'ev, N. K. Gusarova, S. F. Malysheva and B. A. Trofimov, Org. Prep. Proced. Int. 2011, 43, 381-449.

19. C. Zeng, Y. Chen, A. Das and R. Jin, J. Phys. Chem. Lett., 2015, 6, 2976-2986.

20. X. Kang and M. Zhu, Chem. Mater., 2019, 31, 9939-9969.

21. A. V. Naumkin, A. Kraut-Vass, S. W. Gaarenstroom and C. J. Powell, NIST Standard Reference Database 20, Version 4.1, 2012. 
Table of Content

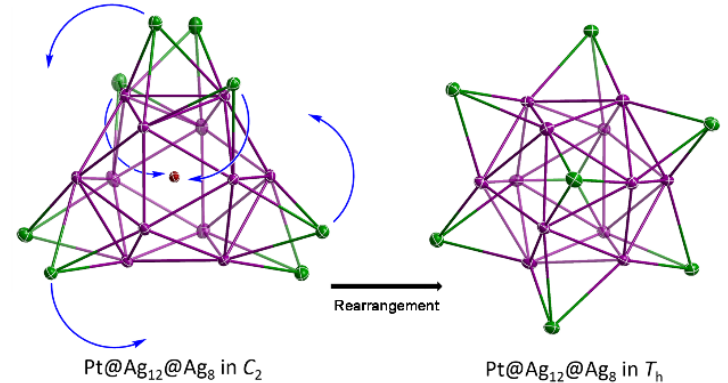

First 8-e, Pt-Ag superatoms protected by Se-donor ligands were synthesized by ligand replacement reaction on its sulfur analogue. The metal framework of $\operatorname{PtAg}_{20}$ changes from low symmetry $\left(C_{2}\right)$ to high symmetry $\left(T_{h}\right)$ via rearrangement of five capping silver atoms. 